\title{
The enrichment of magical thinking through practices among Reiki self-healers ${ }^{1}$
}

\section{Prologue: in the field}

A whispering voice with tone of solemn affirmation broke the silence: 'you have now received your first Reiki tuning.' A group of eight people were sitting still, their chairs in a line, holding their hands in the Gassho position. ${ }^{2}$ The owner of the voice, the teacher of the Reiki course, started to speak again. 'Spirits of all kinds were filling the air as I did the tuning. ${ }^{3}$ It was almost like a rush hour in the city of Helsinki, so crowded with spirits was the space.' She told us that some of these spirits stepped out and took their positions behind the people participants. 'These spirits might be your personal guides on the Reiki-path, or they might have some other personally significant meaning to you'.

Everybody received their own spiritual guides; some got two of them. The spirits represented well-known mythological figures such as Merlin, or characters from different religious traditions, such as the Archangel Michael. Some were just 'ordinary folk', such as the spirits of an old man and a little girl. Some spirits were more like an attribute as pure lightness, or just vague beings; one was simply 'a green creature. ${ }^{4}$

The Reiki Master had started the 45-minute long ritual by beating on a big shamanic drum. She walked around and stopped behind each of us by turn.

1 This study was funded by the Signe and Ane Gyllenberg Foundation. I thank Ilkka Pyysiäinen, Jani Närhi, Mikko Heimola and Pyry Hannila for their helpful comments about this article.

2 In the Gassho position palms are together and fingers are pointing upwards. The position is used when praying or when greeting in Japan and in various Buddhist traditions and among western yoga practices where it is better known by the name of Namaste.

3 The word 'tuning' is my own translation from the Finnish word viritys, which means something like 'not in balance' (as with a musical instrument) and needing to be brought into balance. In English Reiki literature and in scholarly studies the word 'attunement' is used. See, for example, Macpherson 2008. 
Everyone was asked to sit comfortably and to keep their eyes closed or halfclosed. Listening to the drumming and feeling the resonance of the drum roll in the body created a sense of a magical space, partitioning off the big gymnasium, in which the course was taking place. When the drumbeat stopped, the sound of harmonic music arose from the flat-top in the background.

The tuning itself looked like a mime in which the Reiki Master was shaping the air and trying to untie some invisible knots. At times, she pushed and pulled the air upwards and downwards, then twirled the air above, in front of, and behind the participants, one after another. Twice she touched the participants. First she took the hands of a person, opened them so that they made the shape of a bowl, whirled the air over it, blew into the hands and then closed the hands back into the Gassho position. It looked as if she had transferred some transparent essence into the hands of the person. In the final part of the tuning the Reiki Master touched each of the participants by putting her hands on their shoulders. Some reported afterwards that her hands felt icecold; others felt them to be hot. These two acts of concrete touch helped the participants to recall and outline their impressions. The reminiscences of the others might also help to recall one's own impressions, although this recollection could also be an act of mimicry. For example, a vision of one big eye was reported by several of the participants. Also visions of colours and pictures were reported, as well as the hearing of sounds and feeling bodily sensations.

After everybody had verbalised her, or his, experience of the initiation, the teacher showed us the first Reiki symbol: Cho-Ku-Rei. According to the preceding lessons, it was necessary to tune the channels before the Reiki symbols could work as vehicles of healing. Basically, the Reiki healing energy is said to be ready to operate under two conditions. For one thing, the channels have to be opened up by the Reiki Master, and for another, a definite symbol is needed to activate the Reiki energy through the tuned channels. Cho-Ku$R e i$ is the symbol used when healing oneself or others by means of physical contact. The symbol was enacted first by drawing it on paper, and then in the air. In healing practice, the symbol is drawn on the healer's palms. The other symbol was given the day after the tuning. It was called Sei Hei Ki, and it is designed for use when healing emotional states or attitudes. ${ }^{5}$ We were told that it could be too much for somebody to get two tunings in one day. We were also reminded to drink plenty of water during the weekend, as it is believed to help the energies to flow. 


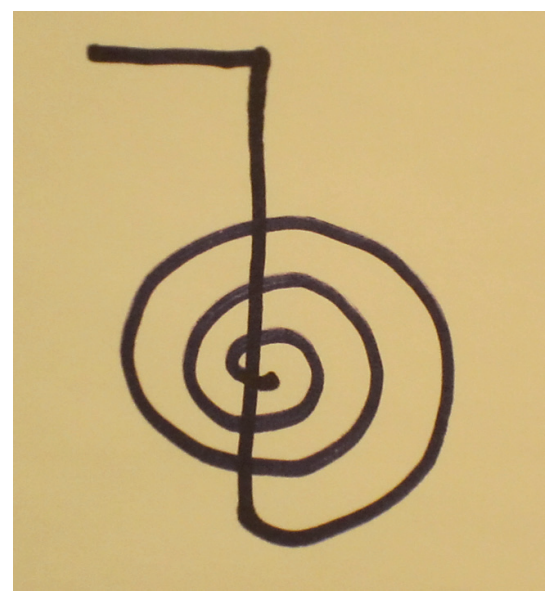

The first symbol to be learned, Cho-Ku-Rei.

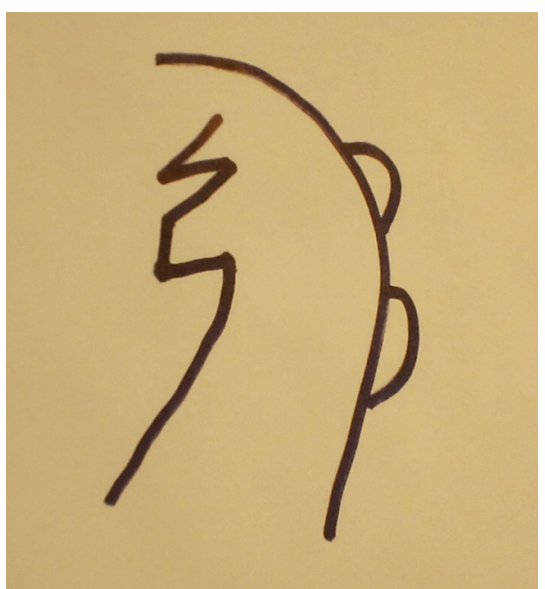

The symbol when healing mind, Sei He Ki.

The lessons before the tuning prepared the trainees for the magical act. Questions such as where does Reiki energy come from? what kind of energy is it? and what are the benefits of practising Reiki? were on the agenda. We were told that Reiki came to the western world via Hawaii. A Hawaiian-born Japanese woman, Hawayo Takata (1900-80) learned the philosophy and practice of Reiki in Japan (1935-7) under the guidance of Chujiro Hayashi (1880-1940), who was one of the first students of Usui Mikao (1865-1926), the founder of the Reiki symbols. ${ }^{6}$ The importance of lineage is emphasised among Reiki Masters (teachers) and practitioners. At the head of the lineage is the founder of Reiki, Mikao Usui, and in the Western lineage then comes Chujiro Hayashi, and Haway Takata follows. Finnish Reiki Masters usually have at least five names in the lineage before them.

There are different interpretations of the historical origins of Reiki. Some practitioners espouse more esoteric interpretations, others focus on the techniques (handpositions, symbols, tuning the channels) which Usui Mikao passed on to Hawayo Takata. Some followers of Mikao Usui have regenerated Reiki on the basis of their own experiences, others have respectfully devoted themselves to Usui Mikao's work by continuing the tradition according to his original instructions. But all the different branches of Reiki represent one of two major traditions: the traditional Japanese Reiki and Western Reiki. The difference between these traditions is said to lie in the exercise of intuition and meditation, which are more typical for Japanese Reiki. In Japan, there are nowadays six Reiki lineages independent of Usui's Reiki Healing Society. In this article the detailed background knowledge of the history of Reiki and the different lineages of teachings are not relevant to the analysis. 
The meaning of the word 'reiki' comprises of two elements based on two words the meanings of which are then united. Rei means spiritual and $k i$ means life force. ${ }^{7}$ Reiki is par excellence a healing method based on the belief that there is a universal healing energy which can be channelled through the hands. It is a common belief among Reiki practitioners that the energy in question is actually the purest loving energy in the whole cosmos. People worked with it thousands of years ago, for example in ancient Egypt, and then it was forgotten. ${ }^{8}$ According to this belief, such energy is 'dormant' within us, and has to be reactivated. Once activated through initiation, it is in use for the rest of one's life.

The Reiki teacher ${ }^{9}$ of this weekend course was pedagogically very skilful; a talented speaker, supportive and inclusive. Her attitude was positive and she performed in a lively manner. She spoke in dialect. Her appearance was folksy and accessible. She was not normative, but rather seemed flexible in relation to the different interpretations concerning Reiki. She rather encouraged us to use intuition when practising Reiki. ${ }^{10}$

She told us stories which were easy to remember either due to one, exceptional element or first-hand experience. For example, she told us the story of a lawnmower and a woman who called her one day and asked: 'is it really true that you can give Reiki to anything?' 'Yes', the Reiki teacher answered. After a while the phone rang again, and the previous questioner said that she had just used Reiki on the lawnmower, 'and it works'. Many similar narratives were told. They all included concrete problems which were then solved by means of Reiki energy. 'It works' seem to be the best evidence of the authenticity of pure Reiki healing energy. She also told us about very touching, traumatic events that had happened to her. These stories were also easy to remember as they affected everyone present. The unspoken message beyond these sad stories

7 The original meaning of word 'reiki' has also become a matter of speculation.

8 Such narratives of 'a lost paradise' or 'a golden age long ago' are well-known in many religious traditions.

9 Reiki teachers have gone through first, second and third stages of Reiki initiations before they are able to teach others.

10 The concept of intuition is very popular in everyday speech and among spiritual healing practices. Usually intuition means, in these contexts, a kind of pure and genuine knowledge within us. The source of intuitive knowledge is either in one's own religious tradition, or it might be channelled through some entity from outer space (for example God, the Holy Ghost, a cosmic entity, a Reiki spirit). The easiest way to use intuition is to just trust in thoughts that come to mind in relaxed circumstances. (Field diary 1/2010.) 
was 'if she can survive happily through such difficult ordeals, then Reiki must be a very powerful tool'.

The Reiki teacher also told us some examples of when she herself had 'certainly been in the wrong mood and had not been able to even think about Reiki'. In that way she emphasised that Reiki might not work if one is not in a well-balanced state of mind. She counselled us to keep Reiki on our mind also after the course. 'The challenge I am facing every day is how to integrate these subtle, positive practices into everyday living with children, and home life.'

\section{Reiki}

The spread of Reiki has been rapid in the Western world since 1980, when Hawayo Takata died. She kept the Reiki symbols in secret and passed on the teachings of Reiki only as an oral tradition. Takata initiated 22 Reiki Masters, who in turn have initiated several new Reiki Masters. The first Finnish Reiki Master started her courses as early as 1985 . It is estimated that there are tens of thousands of trainers in Finland, and millions all over the world. ${ }^{11}$ Nowadays the symbols and detailed instructions of the hand positions along with illustrative pictures are available to all via many Reiki handbooks and web pages. ${ }^{12}$ Some books give a step-by-step description of how the initiation into Reiki mastery is done. Still, the tunings of the Reiki channels have to be made by the Reiki Master. It cannot be self-made.

Training in traditional Reiki has three degrees (levels). No special background or credentials are needed to receive training, but the preceding levels have to be performed before proceeding to the next level. The prices of weekend courses vary between 200 and 500 euros in Finland. Personal guidance for becoming a Master costs 1,000-2,000 euros a year. It includes several personal meetings with a Reiki Master, and becoming a Master can take some years.

11 Unofficial estimates of trainees vary, but according to the 2007 National Health Interview Survey, which included a comprehensive survey of CAMs (Complementary and Alternative Medicines) used by Americans, more than 1.2 million adults had used an energy healing therapy, such as Reiki, in the previous year.

12 The first book in English was William Lee Rands's Reiki: The Healing Touch, published in 1980. The first Reiki book by a Japanese Reiki Master (Hiroshi Doi) Modern Reiki Method for Healing was translated and published in English in 2000. 
In this article, Reiki is an example of a spiritually based healing context, which offers an entry into the magical thinking through the ritual initiation. There are several practices like Reiki in the field of new spirituality. Their backgrounds are situated in a variety of religious traditions, although many religious ideas in the field are based on assimilation of ideas and practices familiar in Eastern religious traditions. ${ }^{13}$

Why is Reiki so particularly famous in the field? It would seem that Reiki is very flexible and easily integrated to other practices. Several persons I have met in the field who have practised or are practising Reiki have usually mixed it with elements from other healing practices. ${ }^{14}$ One factor, furthermore, which explains the popularity of Reiki has to do with healing. Healing, as well as illness and sickness, involving pain and relief from pain, are universal experiences felt by everyone. Complementary and alternative ways of healing are as popular among ordinary folk now as they have been throughout the history of medicine. Even medical nursing staff participate in Reiki courses in their leisure time. One reason for the popularity might also be that Reiki courses are open to everybody. Everybody can learn to heal. After initiation, participants are promised, and believed, to be rewarded for the ability to heal themselves and those near to them with the help of cosmic energy.

\section{The study}

In this article I study what I call the enrichment of magical thinking among Reiki self-healers. By the term 'enrichment', I refer to an observable thickness (or density) of spontaneous reasoning going along lines of magical trains of thought. This includes, for example, assumptions of agency and magical contagion.

At first my research interests focused on intuitive presumptions beyond expectations of healing in general. When in the field, I soon realised that intuitive thinking prevailed over reasoning and behaviour. Actually, it looked like the intention was to stimulate one's mind towards intuitive thinking,

13 Overview studies concerning the new spirituality (or New Age) include contributions by, for example, Wouter J. Hanegraaff (1996) Paul Heelas (1996) Meredith McGuire (1998), Linda Woodhead and Paul Heelas (2000) and Steven Sutcliffe (2003).

14 Besides observation of Reiki courses, my ethnographic data includes notes and material from mind-body-spirit festivals in Finland (Minä Olen -messut 2001, 2009, 2010, 2011, Hengen ja tiedon messut 2008, 2009, 2011). 
and vice versa, to relieve the mind from analytical and reflective thinking. New questions followed: What were the features that encourage intuitive and magical thinking during Reiki courses? How did the routine performance of magical thoughts happen? What was the impetus to continue practising magical thinking?

My theoretical frame of reference goes back to studies about the architecture of mind, and especially those concerning the duality of mind, known as two minds theory, or dual-process theory. My approach is based on latest experimental findings in cognitive and social psychology concerning both intuitive, magical thinking and reflective, analytical thinking ${ }^{15}$ (Chaiken \& Trope 1999; Epstein 1994; Epstein \& Pacini 1999; Evans 1989, 2008, 2010; Evans \& Over 1996; Hammond 1996; Kahneman 2011; Lieberman 2003; Nisbett et al. 2001; Reber 1993; Sloman 1996; Stanovich 1999). In the study I mix qualitative data and analysis with a quantitative frame of reference. My study belongs to the field of the cognitive science of religion (henceforth CSR), which is a relatively new multidisciplinary research programme. ${ }^{16}$

The analytical frame of reference includes three stages, or steps. The first stage is the 'entry into the magical world', the second is the 'acquisition of magical skills', and the third is the 'development of magical expertise'. This three-step model is actually analogous with the general characteristics of skill acquisition (see Fitts 1954, Fits \& Posner 1967, Anderson 2000), which is the model used in the study of the cognitive structure of expert performance. The study of cognitive learning structures and acquisition of skills is often focused on technical skills and the automation of skills until the competence in question is acquired (as for example in learning to drive a car). The steps of the skill-learning model are; 1) the cognitive stage, 2) the associative stage and 3) the autonomous stage.

The famous '10,000 Hour Rule' is a research finding in the field. According to this rule, it takes approximately 10,000 hours of deliberate practice to master a skill (Ericsson 1996, Ericsson et al. 2006). In the study, conducted in Berlin 1993, K. Anders Ericsson and his colleagues divided students into three

15 Cognitive and social psychology have both studied the same subject, unaware of each other until 2006 when Jonathan St. B. T. Evans and Keith Frankrish organised the first major conference 'In Two Minds: Dual-process Theories of Reasoning and Rationality' and brought together scholars from different disciplines to discuss the contributions to dual-process theory.

16 The history and the developmet of CSR is nicely presented in, for example, Aku Visala's award-winning study Religion Explained? A Philosophical Appraisal of the Cognitive Science of Religion (2009, published by Ashgate in 2011). 
groups ranked by excellence at the Berlin Academy of Music, and then correlated achievement with hours of practice. They discovered that the best had put in about 10,000 hours of practice, the good 8,000 and the average 4,000 hours. In later research this rule was applied to other disciplines (sports, the arts, science) and the similar results were found (Ericsson et al. 1993, 2006).

The question of expertise might be relevant also in the context of the study concerning the enrichment of magical thinking. The development of expertise and virtuosity might not be characteristics only of gifted musicians, chess-masters or top-level athletes, which are the groups most studied. Would anybody who practices anything deliberately (for 10,000 hours) become a master in the skill?

In the context of dual-process theory and the recent findings concerning magical thinking, I am looking for the enrichment of magical thinking and development in expertise in the context of Reiki case. Before that, I will give a brief overview of the theoretical frame of reference of this study.

\section{Two minds}

Two fundamentally different ways of thinking - intuitive and reflective-have been a subject of interest and speculation throughout the history of science (e.g. Spinoza, Leibniz, Locke, Schopenhauer, Freud, James). The rapid advances in studies focusing on the mind ${ }^{17}$ support the propositions of these early scholars. Over the past 20 years, there has been an accumulation of a considerable body of empirical evidence for dual processing in learning, reasoning, decision-making, and social cognition (Evans \& Frankish 2009, Evans 2010). While the emphasis and details differ somewhat between theorists, there is a broad consensus that the two processes (minds) might include the set of features itemised here.

Intuitive thinking evolved early; it is fast, spontaneous, automatic, concrete, heuristic, holistic, contextualised, mainly unconscious, and it is biased by personal emotions, experiences, beliefs, associations and generalisations. Analytical thinking, by contrast, evolved relatively recently and is slow, controlled, reflective, logical and abstract. By means of systematic processing, more or less, humans can correct and transpose reasoning based on intuitive presumptions. At times, the intuitive and the reflective minds might also

The general background for cognition-based approaches are the cognitive revolution and the rapid development of computer science from 1950 on onwards. The rapid development of technical innovations (for example, audiovisual techniques and brainscanning) affords an opportunity in the experimental studies of mind to discover knowledge which was based earlier on observation and introspective thinking. 
compete with each other. The latest findings indicate that the unconscious, intuitive mind is more in charge of our so-called conscious thinking than we have hitherto believed. (Wegner 2002, Evans \& Frankish 2009, Evans 2010.) The processing of the intuitive mind is unobserved. For example, stereotypical presumptions might direct our reasoning and behaviour in ways we consciously do not accept.

\section{The study of religions and the intuitive mind}

Intuitive thinking has been the primary target of scholars in the field of CSR since the beginning of this recent inter-disciplinary research, as actual religiosity is by and large intuitive. ${ }^{18}$ Many CSR scholars have touched on the question of the basic duality of the mind in pursuance of other contributions to the research programme. ${ }^{19}$ Ilkka Pyysiäinen, particularly, has discussed in detail the distinction between what is intuitive and what explicit in religious thought in general and specifically in relation to counter-intuitive concepts and agency (2004a, 2004b, 2005, 2009). He clarified the wide field of dualprocess studies by listing eleven different dichotomies characterising the two systems of reasoning (Pyysiäinen 2004b). ${ }^{20}$ Pyysiäinen has emphasised that the cognitive functions supported by 'the A-system' (intuitive thinking) are, for example, intuition, fantasy, creativity, imagination, visual recognition, and associative memory (Pyysiäinen 2004b: 135, see also Sloman 1996). These functions are often observable in religious contexts. ${ }^{21}$

Todd Tremlin (2006: 172-82) has been involved in discussions within CSR concerning how these two minds are differentiated from each other in religious thought. Dan Sperber's (1997, see also Mercier \& Sperber 2009) contributions deal with cognitive architecture from the view of an evolutionary and massively modularist framework. For example; the minimal counter-Intuitiveness hypothesis (MCI) of Pascal Boyer (Boyer 1994, 2001; Boyer \& Ramble 2001; Barrett \& Nyhof 2001), the notion of hypersensitive agent detection device (HADD; Guthrie 1993, Barrett 2000), the intuitive theism hypothesis of Deborah Kelemen (1999a, 1999b, 1999c, 2004; Kelemen \& DiYanni 2005), the hazard precaution model of ritual behaviour by Boyer and Pierre Lienard (2006a, 2006b), E. Thomas Lawson's and Robert N. McCauley's ritual form hypothesis (1990), the model of religiosity theory of Harvey Whitehouse (2004) and the notion of afterlife belief put forward by Jesse M. Bering (2002).

20 There have been several kinds of concepts about the intuitive and the analytical mind. For example, automatic vs. controlled, heuristic vs. analytical, reflexive vs. reflective, associative vs. rule-based, implicit vs. explicit etc. (Pyysiäinen 2004b). Furthermore, Finnish scholars like Jani Närhi have contributed to the research on intuitive thinking in connection with paradise representations, while Elisa Järnefelt is revising her dissertation concerning creationist thinking (Närhi 2008, 2009). 
Close to the dual-process model is the observation that natural intuitions tend to overwrite theological doctrines and drive behaviour. CSR scholar Justin Barrett has termed the theory concerning the difference between idealized theological doctrines and the beliefs people actually have, as 'theological correctness'. Barrett argues that there seem to be two parallel God concepts. The basic concept is used in real-time, fast processing of information, while the learned, more complex concepts are used when theological doctrines are explicated (Barrett 1999, Barrett \& Keil 1996). What we think we believe in, and what we spontaneously assume when there is no time or space for rational thinking, are fundamentally based on two different types of reasoning. Later Barrett (2004) argues, on the basis of diverse studies from CSR and cognitive psychology, that religious belief is natural. It is intuitively satisfying because it is cognitively easy to accept in the frame of cognitive constraints (Barrett 2004: 17).

\section{Mood and cognition}

Besides cognitive constraints in the processes of intuitive and reflective thinking, theories of mood and cognition from social psychology are relevant in the context of this study. Experimental studies of 'positive affect' (PA) and 'faith in intuition' (FI) have predicted superstitious beliefs and sympathetic magic (King et al. 2007, Hicks et al. 2010) and, thus, are relevant in this study. Like the studies concerning subjective rationality (first identified by William James in 1893), also called the feeling of meaning, which pertains to a feeling about an event or experience which one has found to feel 'right'. This feeling of rightness is responsible for our perception that experiences make sense (Mangan 2000). How does mood direct cognition, and what kind of mood is needed to activate the process of enrichment of magical thinking? According to CSR scholar Pascal Boyer (1996: 626), 'enrichment arises from the broad initial, intuitive principles, together with the expectations that they trigger, towards the complex theoretical structures' (as for example religious doctrines).

\section{Magical thinking}

The terms 'magic' and 'magical thinking' have a wide range of meanings in the earlier history of the study of religion. Also, many interesting hypotheses have been presented in the long tradition of scholarly discussions concerning magic. In what follows I will highlight just three names from the history, as the definitions of these scholars have proved still to be applicable a hundred years later. Two of them are so-called Victorian anthropologists, Edward B. Tylor (1871) and James Frazer (1911), who were the first to define 'the uni- 
versal laws of magic'. They were both looking for patterns of thought underlying magical actions. Tylor pointed to the importance of analogical reasoning and he, in accordance with the evolutionist framework, claimed that primitive people replace cause and effect with associations of ideas based on similarity, contagion and contiguity. Frazer elaborated Tylor's ideas on magic into the famous typology of sympathetic magic. The law of contagion or contact is based on the principle that two things once in contact will retain a connection regardless of time or space. Whereas the law of similarity is based on the principle that like attracts like. For example, the similarity between plant parts and body parts indicated their efficacy in treating diseases in those body parts.

The French anthropologist and sociologist Marcel Mauss (1950) emphasises that the concept of mana is also an important element of magical thinking. He pointed out that the essence (mana) is unitary, and thus, remains in every part taken from the whole (pars pro toto). The concept of mana, according Mauss, connoted the driving force, or essence, that travels along the lines determined by sympathy (Mauss 1972: 117).

In the early twentieth century, magical thinking was situated at a lower grade in the hierarchy of the evolution of human mental processing. Magical thinking was seen as fundamentally different from the Western style of thought. It was also believed among Western scholars that there is a major difference between magic and religion, and that the primitives were still too immature to be able to practise Christian monotheist religious thinking. The tenacious belief that there is no need for magical thinking as education increases the level of knowledge, is still alive. The latest evidence, nevertheless, supports the argument that humans, regardless of education or secularisation, are apt to think in magical ways, as the two minds theory predicts. (Wegner 2002, Evans 2010.)

In the late twentieth century Carol J. Nemeroff, Paul Rozin and colleagues found that Frazer's, Tylor's and Mauss's principles of magic seem to work in the thinking of educated, Western adults (Rozin et al. 1986; Rozin \& Nemeroff 1990; Nemeroff 1995; Nemeroff \& Rozin 1994, 2000) The findings are very interesting and open up our understanding concerning magical modes of thinking, also in non-religious contexts. Of particular interest were studies concerning different kinds of disgust. Their findings indicate, for example, that people conflate germs with evil, as reflected in, for example, refusing to wear the sweater, said to have belonged to Hitler or some serial killer, even if it was sterilized. Emotions seemed to override rational thinking.

The law of contagion holds that physical contact between the source and the target results in the transfer of some effect or quality (essence) from the 
source to target. Qualities may be physical, mental, or moral in nature, and negative or positive in valence. ${ }^{22}$ 'The most relevant feature of a source-in the mind of the perceiver or practitioner-is what is believed to be transmitted. Both properties and modes of transmission may be metaphorical.' (Nemeroff \& Rozin 2000: 4.)

According to Rozin and Nemeroff beliefs about negative contagion are more general than positive ones (Rozin \& Nemeroff 1990: 208). And further, negative beliefs are stronger in situations of conflict. Contact with a host of negative things (e.g. unknown strangers, malicious others, their possessions or bodily residues, death and physical corruption of any kind) is felt to be physically dangerous and/or morally debasing to the person. Contamination and pollution are the terms used when an essence and its effect are negative in valence. There are also scientifically validated instances of contagion, for example, in germs and the transmission of illnesses.

Still, magical contagion is far broader in terms of what may be transmitted and how (Nemeroff \& Rozin 2000: 4). 'In the broader concept transmissible properties include physical or moral properties and may be harmful or beneficial. Thus goodness and evil are as transmissible as influenza.' (Nemeroff 1995: 147.) Contact with smaller set of positive things such as loved ones or personifications of goodness or holiness (for example, the Virgin Mary), or their possessions or residues, can be felt to enhance or elevate the self (Nemeroff \& Rozin 2000: 7).

Nemeroff, Rozin and their colleagues state that magic is an intuitive, and possibly universal, aspect of human thinking, ranging from spontaneous, vague, 'as if' feelings, all the way to explicit, culturally taught beliefs. Magical thinking involves the sympathetic principles of similarity and contagion, and the notion of an imperceptible force (essence) that drives, carries, or provides the mechanism for effects (Nemeroff \& Rozin 2000).

What is magical thinking in terms of intuitive processing? Magical thinking is based mainly on the processes of the intuitive mind, although it also represents inferences typical of reflective thinking. For example, different kinds of explanation models and 'folk-theories' concerning the unseen world, or spiritual beings and their aims and wills, are popular 'analytical' concepts in the new spirituality. ${ }^{23}$ In the religious context intuitive, magical thinking

The term 'valence' is used in psychology in discussing emotions. It means the intrinsic attractiveness (positive valence) or aversiveness (negative valence) of an event, object, or situation.

23 Folk-theories differ from scientific theories, for example in evidential values. The word 'theory' in everyday speech means the possible hypothesis or explanation of 
is highly ranked because it is cognitively effortless due to the nature of concepts. Intuitive decisions are not, however, unconscious decisions; they are rather based on feeling instead of reflection (Evans 2010: 166). 'When we "go with our gut" we choose to do what feels right. Reflective thought is a slow, cognitively expensive, and tiring process. Intuition and feeling are fast and easy bases for decision-making. The feeling that we do things because we consciously intend to do them has been shown to be a powerful illusion. We can and do confabulate explanations for our own behaviour, giving ourselves

and others false introspective reports of the reasons for our actions.' (Evans 2010: 169.)

As intuitive thinking is, among other things, strongly context-bound, spiritually-based alternative therapies or religious environments are the most useful contexts in which to study the delivery of magical meaning-making. That is, magical thinking is best observed through spontaneous speech, which is shared in the positive atmosphere created during the gatherings of those who are interested in holistic healing.

In the following anlysis I will observe the data from Reiki training courses by focusing on magical thinking and the contextual cues which support and enrich it. The data of the case-study has been collected in the field by way of participant observation which includes tape-recordings.

\section{Three stages of analysis}

The analysis of enrichment of magical thinking among Reiki practitioners is presented in the frame of three stages or steps. As explained above, the stages progress as follows: the first stage is the entry into magical world, the second involves the acquisition of magical skills, and the third development of magical expertise. An analogy with the general characteristics of skill acquisition model concerns a three-stage process of becoming expert in some skill.

This analytical frame of reference, in the context of dual-process theory and the new findings concerning classical definitions of magical thinking, makes the observation of the process of enrichment of magical thinking visible. Through the analysis I try to understand what are the contextual cues

some phenomenon. Scientific theories have to argue their claims and prove them according to the criteria of the research community. Lay persons' 'theories' are usually not challenged by counter-criticism. 
supporting magical, intuitive thinking; how the magical thinking is routinised, and what is the impetus to continue the magical practices.

\section{The first stage: the entry into the magical world}

In the data, participating in Reiki training and the act of accepting the initiation through the tuning ritual is an entry into the magical world of thinking. In the initiation ritual and during the healing practices everybody gets the subjective experience of the working of Reiki energy. The Reiki Master reinforces the view that after the initiation, besides the ability to heal, the participants are connected to the unseen world via Reiki energy, and that gives them an ability to listen to their own inner, intuitive voice (or the voices of different spiritual beings). Supposedly, these people, by virtue of participating in the Reiki course, are apt to think intuitively. They come to the course on their own initiative, and they are curious to learn more about Reiki. Some of them have had positive experiences of Reiki treatment, and some have heard about Reiki from close relatives or friends. The educated guess here could be that very sceptical thinkers do not take part in weekend Reiki courses. ${ }^{24}$

The source of magical contagion is universal Reiki energy. It is transferred during the initiatory ritual from its cosmic source to the Reiki trainee with the help of the Reiki Master. Actually, according to Reiki doctrine, the external spirit does not overtake the body as in spirit possession. Humans are rather 'the channels' through which spiritual power can operate.

On the whole, the atmosphere in the course was very positive. Many had positively loaded expectations of the Reiki course beforehand. During the jointly shared time, the group became closer, and positive affects strengthened among participants by means of social influence. ${ }^{25}$ Positive affects (PAs), faith in intuition (FI) and feeling in meaning supported the enrichment of intuitive, magical thinking as the experimental studies predicted. Narratives told by the teacher (Reiki Master), evidence heard ('it works') and the approving attitude of the teacher created positive atmosphere felt in the field.

Although many elements typical of new spiritual movements (e.g. soft lights, candles, the scent of incense) were absent, as the course took place in the gymnasium of an ordinary school, the use of drumming created the feeling of a sacred space. A shaman drum does not feature in original Reiki prac-

The psychologist Marjaana Lindeman (et al.) has divided people into supernaturalthinkers and sceptical-thinkers on the strength of the results of survey studies (Lindeman \& Aarnio 2006, Lindeman \& Saher 2007).

25 The way in which our own views are affected by those of other people around us is known as social influence (Evans 2010: 150). 
tices, but several Reiki Masters have integrated their Reiki practice with items or practices from other spiritual traditions. (Melton et al. 1990, Macpherson 2008.)

According to the expertise model, subjects develop a declarative encoding (knowledge about facts and things) of skill during the first stage. That is, they commit to memory a set of facts relevant to the skill. Learners typically rehearse these facts as they first perform the skill (Anderson 2000: 281; Fitts \& Posner 1967: 11-15). Practising the new skills, step by step, first by drawing the symbol on paper and in the air, then learning the hand positions, and finally practising the healing in group healing sessions, where each in turn lay down on the floor, others keeping their hands on certain places in the body, is concrete and practical and includes 'ordinary' acts. At the same time, with these bodily practices, the meaning of the practices is associated with the flow of the universal healing energy, Reiki. At this stage, participants come to understand what Reiki skill is composed of. According to the model first described by Fitts (1954), attention is significant for the acquisition of skill at this point in the process.

At the entry stage not many normative rules were explicated by the teacher. On the contrary, every question was answered with approval and positivity. For example, the question of the source of Reiki energy compared with Christian beliefs presented no problem at all. 'The loving energy covers everything and the source is the same, it just has different names.' The social influence of the group affects our own views, and 'the main reason people believe things is because other people believe them as well, especially when those other people are members of the same social group.' (Evans 2010: 150.)

\section{The second stage: acquisition of magical skills}

The second stage, involving the acquisition of skills, might be seen also as an analogy to the classic ritual-theory of Arnold van Gennep (1909/1960) as this stage of practising the skills is a liminal state (marge in Gennep's vocabulary). The initiation is received, but the future is 'unknown'. In this data the second stage is critical in the sense that probably those not impressed enough, or those facing contradictions with religious or moral beliefs acquired earlier, might decide not to continue practising. ${ }^{26}$

26 Some fragmentary notes from the field point to the conflicts due to negative afterthoughts according to the source of the spirits involved in Reiki initiation. There will be more discussion about negative intuitive thinking in my forthcoming doctoral dissertation. 
Participants have been advised by the Reiki Master to rehearse new skills once a day during at least three weeks at home. Repeated practice leads to automation, as the connections among various elements required for successful performance are strengthened. Through the rehearsal of the Reiki healing technique, the trainers accustom themselves to the magical ways of thinking as they were encouraged during the course.

\section{The third stage: the development of magical expertise}

In the third stage development from novice to master begins. Those trainees who have arrived at this stage, participate in the Reiki II course, the next level. They have practised Reiki technique and they are interested in learning more about Reiki. The difference between the participants in Reiki I and II courses is in behaviour. These are not novices anymore, and they show it by speaking openly about their intuitions (about everything). Explanations based on magical contagion are usual. Narratives of miracles made with the help of Reiki are now told by others than the teacher, as in the first course. Bursts of creativity, fantasy, intuition, and imagination fill the air as participants express freely and spontaneously their thoughts and feelings.

Some of them have done tattoos of Reiki symbols on their skin. Some tell how they drew Reiki symbols on paper and put them in their bras or in clothing, under the pillow, in their wallet, or some other personally significant place. The participants also reveal how they have decorated their homes with symbols. Several, creative ways of using Reiki symbols are compared. The meaning and usage of Reiki symbols have been extended to cover protection, success in love affairs or prosperity. People laugh merrily at each other's ideas for using Reiki in new ways. After the new tunings (opening up new channels for new symbols), participants tell detailed narratives of fantasy travel. Obviously, the atmosphere feeds the imagination of participants. The role of the teacher is smaller than in the 'novice-course'.

It appears that magical causal reasoning has automatised rather quickly among the participants.

Along with magical thinking, normative rules based on intuitive and magical biases are strengthened. This is reflected in the rituals that practitioners have created. Rituals aiming at protection are more usual than in the first stage. Also, cleansing rituals become more important as more complex doctrines are adopted through the reinforcement of magical thinking, due to implicit learning in the new social group. Studies show that we have a fundamental tendency to form ourselves into in-groups and out-groups (Evans 2010: 155). 


\section{Conclusions and discussion}

In this article, I have observed the enrichment of magical thinking in the context of spiritually-based healing which is practised on Reiki courses. ${ }^{27}$ At first, I introduced a piece of ethnography, precisely, the magical act of initiation. During the act the essence of universal Reiki energy is believed to transfer from the cosmic source via the Reiki Master into the student.

The magical ritual seems to follow the line of magical thinking outlined in the studies concerning magical contagion by Nemeroff, Rozin and colleagues.

According to the latest study presented above, magical thinking is included in the processes of intuitive mind in many respects. Classical theories of sympathetic magic have proven to be a part of our natural way of thinking. Experimental studies have shown that the law of contagion seems to operate also in modern people's minds, mostly on unconscious level. Magical thinking is easy, it feels right and it gives the feeling of meaning and control over one's life. In the studied context, positivity, heuristic creativity and a joyful atmosphere were strongly present in contrast to above mentioned studies, which focused mostly on feelings of food disgust and magical thinking about illness virulence, or were observed in the contexts of stressful and uncertain events.

It seems obvious that, in a spiritually-based healing course such as the Reiki training illustrated here, triggers that activate intuitive, magical thinking, are strongly present. The triggers are contextual cues. As the intuitive mind is contextually bound, heuristic processes are easily activated. Context drives cognition, in this case, towards intuitive and magical thinking. Contextual cues support intuitive thinking and biases beyond magical thinking. The atmosphere and social influence are probably the most important factors in creating a context that supports intuitive thinking, as the studies in social psychology have stated. The positive atmosphere needed in a healing context arises on the basis of many elements which are cognitively easy to adopt. These include, for example, emotionally touching cues, personal experiences and narratives which support magical meaning-making. Also the proclaimed intention in the field is to feed the 'intuition' of participants. The concept of

27 This article is based on study and findings to be presented in more detail in my doctoral dissertation: 'Intuitive presumptions beyond expectations according healing, and enrichment of magical thinking in religious contexts' in which I compare the Reiki data with the data collected among the devotees of Nokia Missio. 
intuition in everyday speech and in spiritual contexts is comprehended as one's inner voice, which is believed to be a source of true knowledge.

We can assume that a spiritually-based healing practice, like Reiki, is one possible entry into the world of magical thinking. The enrichment of magical thinking was clearly observable during the timeline of one weekend course, and specially, when compared with the second course, when participants had already practised Reiki techniques and the automation process was going on. The analytical framework of three stages exemplifies the process of enrichment during the Reiki course. In the first stage (entry), those who are interested in, or curious about holistic healing, acquainted themselves with Reiki. Then in the stage of the acquisition of skills, participants deliberately practise their new skills. Those who are willing to continue practising, take part in the next level course, which is the third stage; the development in expertise. From the second course (and the third stage in the analysis) onward, development in expertise begins.

The impetus to continue practices might originate in feelings of joy or other positive feelings, including the experience of learning a healing method. Positive feelings both precede and follow when things are cognitively easy to learn. Everybody can and does learn the skills. Also 'the 10,000 hours rule' is very fascinating to consider in this context, as a path to religious expertise.

Then, a new question occurs: what kind of expert is the magical virtuoso? The characteristics of a magical expert would probably include creativity, fantasy, intuition, imagination and associative, magical thinking. One of the master's aims is to release the mind from (too) reflective thinking, and trust more in intuition. What is then the role of the reflective mind, if practices like Reiki can be felt to enhance or elevate the self? As Gerald Clore and colleagues have put it: 'Although positive mood sometimes leads to better performance in creative tasks, some tests find that a happy mood also leads sometimes to more responses and more errors. Because positive affect may signal success in a task, it may lead to an early exit from any particular stage of the process. This may result in impulsiveness and a tendency to go with whatever responses come to mind, including novel ones. However, creativity also includes relational, holistic, integrative thinking.' (Clore et al. 2000: 46.)

The hypothesis presented here, that some kind of mixture of both implicit and explicit learning (might) play a significant role when explaining why participants of spiritually-based healing practices or similar still continue practices within 'the world of magical thinking', is worth further study.

In this context, Justin Barrett's concept of 'theological correctness' could be seen to be analogous with 'medical correctness', as conceptions and beliefs ac- 
cording to illness and healing depart from those based on analytical, scientific thinking. In the field of spiritually-based healing there are plenty of concepts, practices and beliefs which have little resemblance to official medical practice. On the contrary, intuitive, magical thinking tends to override medical doctrines and drive behaviour. Supposedly, medical sciences do not support holistic ways of thinking, and, when people get ill or sick, the search for meaning behind one's illness arises. Concepts based on intuitive and magical thinking make meanings which feel right and are both cognitively easy and intuitively satisfying. Furthermore, positivity affects health and gives a feeling of control over one's sickness and health.

When observing magical thinking, two views occur. On the one hand the innate cognitive constraints determine what kind of information we are dealing with, and how we are dealing it. On the other hand, contextual cues direct cognition. In this article I focused on contextual cues directing the cognition towards magical thinking, and showed that in the Reiki context, at least, the cues have a supportive role both in the process of enrichment of magical thinking, and in creating the experience of a spiritually guided healing process.

\section{Sources}

Field diary from Reiki courses 1/2010, 2/2010. Data is in trust of author.

Field diary and material from mind-body-spirit festivals. Data is in trust of author. Transliterated tape-recordings from Reiki courses. Data is in trust of author.

\section{References}

\section{Anderson, John R.}

2000 Cognitive Psychology and Its Implications. 5 ed. New York: Worth Publishers.

\section{Barrett, Justin L.}

1999 'Theological correctness: cognitive constraints and the study of religion.' Method and Theory of the Study of Religion 11: 325-39.

2000 'Exploring the natural foundations of religion.' Trends in Cognitive Sciences 4: 29-34.

2004 Why Would Anyone Believe in God? Plymouth: Alta Mira Press.

\section{Barrett, Justin \& Frank Keil}

1996 'Anthropomorphism and God concepts: conceptualizing a non-natural entity.' Cognitive Psychology 31: 219-47. 


\section{Barrett, Justin \& Melanie Nyhof}

2001 'Spreading non-natural concepts: the role of intuitive conceptual structures in memory and transmission of cultural materials.' Journal of Cognition and Culture 1 (1): 69-100.

\section{Bering, Jesse $M$.}

2002 'Intuitive conceptions of dead agent's minds: the natural foundations of afterlife beliefs as phenomenological boundary.' Journal of Cognition and Culture $2(4): 263-308$.

\section{Boyer, Pascal}

1994 The Naturalness of Religious Ideas: A Cognitive Theory of Religion. Berkeley: University of California Press.

1996 'Causal understandings in cultural representations: cognitive constraints on inferences from cultural input.' In: Dan Sperber, David Premack \& Ann James Premack (eds), Causal Cognition. 615-44. Oxford: Oxford University Press.

2001 Religion Explained: The Evolutionary Origins of Religious Thought. New York: Basic Books.

\section{Boyer, Pascal \& Pierre Lienard}

2006 'Why ritualized behavior? Precaution systems and action-parsing in developmental, pathological and cultural rituals.' Behavioral and Brain Sciences 29 (6): 595-650.

\section{Boyer, Pascal \& Charles Ramble}

2001 'Cognitive templates for religious concepts: cross-cultural evidence for recall of counter-intuitive representations.' Cognitive Science 25: 535-64.

\section{Chaiken, Shelley \& Yaacov Trope}

1999 Dual-Process Theories in Social Psychology. New York: The Guilford Press.

Clore, Gerald L. \& Leonard L. Martin

2000 Theories of Mood and Cognition: A User's Handbook. London: Lawrence Erlbaum.

\section{Epstein, Seymor}

1994 'Integration of the cognitive and psychodynamic unconscious.' American Psychologist 49: 709-24.

\section{Epstein, Seymor \& Rosemary Pacini}

1999 'Some basic issues regarding dual-process theories from the perspective of cognitive-experiental theory.' In: Shelly Chaiken \& Yaacov Trope (eds), Dual-Process Theories in Social Psychology. 462-82. New York: The Guildford Press.

Ericsson, K. Anders (ed.)

1996 The Road to Excellence: The Acquisition of Expert Performance in the Arts and Sciences, Sports, and Games. Mahwah, NJ: Lawrence Erlbaum Associates.

Ericsson, K. Anders, Neil Charness, Paul J. Feltovich \& Robert R. Hoffman (eds) 2006 The Cambridge Handbook of Expertise and Expert Performance. Cambridge: Cambridge University Press. 


\section{Ericsson, K. Anders, Ralf Th. Krampe \& Clemens Tesch-Römer}

1993 'The role of deliberate practice in the acquisition of expert performance.' Psychological Review 100 (3): 363-406.

Evans, Jonathan St. B. T.

1989 Bias in Human Reasoning: Causes and Consequences. Brighton: Erlbaum.

2008 'Dual-processing accounts of reasoning, judgement and social cognition.' Annual Review of Psychology 59: 255-329.

2010 Thinking Twice: Two Minds in One Brain. Oxford: Oxford University Press.

Evans, Jonathan St. B. T. \& Keith Frankish (eds)

2009 In Two Minds: Dual Processes and Beyond. Oxford: Oxford University Press.

Evans, Jonathan St. B. T. \& David E. Over

1996 Rationality and Reasoning. Hove: Psychology Press.

Fitts, Paul M.

1954 'The information capacity of the human motor system in controlling the amplitude of movement.' Journal of Experimental Psychology 47: 381-91.

Fitts, Paul M. \& Michael I. Posner

1967 Human Performance. Belmont, CA: Brooks/Cole.

Frazer, James

1911 The Golden Bough: A Study in Magic and Religion. Part I: The Magic Art and the Evolution of Kings, vol. 1. 3rd ed. London: MacMillan and Co. Ltd.

\section{Gennep, Arnold van}

1960 The Rites of Passage. Chicago: University of Chicago Press. (First published in French in 1909.)

\section{Guthrie, Stewart}

1993 Faces in the Clouds: A New Theory of Religion. New York: Oxford University Press.

\section{Hanegraaff, Wouter J.}

1996 New Age Religion and Western Culture: Esotericism in the Mirror of Secular Thought. Leiden: E.J. Brill.

\section{Hammond, Kenneth R.}

1996 Human Judgment and Social Policy. New York: Oxford University Press.

\section{Heelas, Paul}

1996 The New Age Movement. Oxford: Blackwell Publishers Ltd.

Hicks, Joskua A., Chad M. Burton, David Cicero, Jason Trent \& Laura A. King

2010 'Positive affect, intuition, and feeling of meaning. Journal of Personality and Social Psychology 98 (6): 967-79.

James, William

1893 The Principles of Psychology, vol. 1. New York: Holt.

\section{Kahnemann, Daniel}

2011 Thinking, Fast and Slow. London: Allen Lane.

\section{Kelemen, Deborah}

1999a 'Functions, goals and intentions: children's teleological reasoning about objects.' Trends in Cognitive Sciences 12: 461-8. 
1999b 'The scope of teleological thinking in preschool children.' Cognition 70: 24172.

1999c 'Why are rocks pointy? Children's preference for teleological explanations of natural world.' Developmental Psychology 35: 1440-53.

2004 'Are children "intuitive theists"? Reasoning about purpose and design in nature.' Psychological Science 15: 295-301.

\section{Kelemen, Deborah \& Cara DiYanni}

2005 'Intuitions about origins: purpose and intelligent design in children's reasoning about nature.' Journal of Cognition and Development 6 (1): 3-31.

King, Laura, Chad M.Burton, Joshua A. Hicks \& Stephen M. Drigotas

2007 'Ghosts, UFOs, and magic: positive affect and the experiental system.' Journal of Personality and Social Psychology 92 (5): 905-19.

Lawson, E. Thomas \& Robert N. McCauley

1990 Rethinking Religion: Connecting Cognition and Culture. Cambridge: Cambridge University Press.

\section{Lieberman, Matthew D.}

2003 'Reflective and reflexive judgment processes: a social cognitive neuroscience approach.' In: Joseph P. Forgas, Kipling D. Williams \& William von Hippel (eds), Social Judgments: Implicit and Explicit Processes. 44-67. New York: Cambridge University Press.

\section{Lindeman, Marjaana \& Kia Aarnio}

2006 'Superstitious, magical, and paranormal beliefs: an integrative model.' Journal of Research in Personality 41 (4): 731-44.

\section{Lindeman, Marjaana \& Marieke Saher}

2007 'Vitalism, purpose and superstition.' British Journal of Psychology 98 (1): 33-44.

Macpherson, Judith

2008 Women and Reiki: Energetic/Holistic Healing in Practice. London: Equinox Publishing Ltd.

\section{Mangan, Bruce}

2000 'What feeling is the "feeling of knowing"?' Conciousness and Cognition 9: 538-44.

Mauss, Marcel

1972 A Theory of Magic. London: Routledge \& Kegan Paul Ltd. (First published in 1950.)

\section{McGuire, Meredith}

1998 Ritual Healing in Suburban America. New Brunswick: Rutgers University Press.

Melton, Gordon J., Jerome Clark \& Aidan A. Kelly

1990 New Age Encyclopedia: A Guide to the Beliefs, Concepts, Terms, People, and Organizations That Make Up the New Global Movement toward Spiritual Develoment, Health and Healing, Higher Consciousness, and Related Subjects. Detroit: Gale Research. 


\section{Mercier, Hugo \& Dan Sperber}

2009 'Intuitive and reflective inferences.' In: Jonathan St. B. T. Evans \& Keith Frankish (eds), In Two Minds: Dual Processes and Beyond. 149-70. Oxford: Oxford University Press.

\section{Närhi, Jani}

2008 'Beautiful reflections: the cognitive and evolutionary foundations of paradise representations.' Method \& Theory in the Study of Religion 20 (4): 339-65.

2009 Honey Flows through Fertile Valleys: The Cognitive and Evolutionary Foundations of Paradise Representations. Helsinki: University of Helsinki, Department of Comparative Religion.

\section{Nemeroff, Carol J.}

1995 'Magical thinking about illness virulence: conceptions of germs from "safe" versus "dangerous" others.' Health Psychology 14 (2): 147-51.

\section{Nemeroff, Carol J. \& Paul Rozin}

1994 'The contagion concept in adult thinking in the United States: transmission of germs and interpersonal influence.' Ethos 22 (2): 158-86.

2000 'The makings of the magical mind: the nature and function of sympathetic magical thinking. In: Karl S. Rosengren, Carl N. Johnson \& Paul L. Harris (eds), Imagining the Impossible: Magical, Scientific, and Religious Thinking in Children. 1-34. Cambridge: Cambridge University Press.

\section{Nisbett, Richard E., Kaiping Peng, Incheol Choi \& Ara Norenzayan}

2001 'Culture and systems of thought: holistic versus analytic cognition.' Psychological Review 108: 291-310.

\section{Pyysiäinen, Ilkka}

2004a 'Folk religion and theological correctness.' Temenos 39-40: 151-65.

2004b 'Intuitive and explicit in religious thought.' Journal of Cognition and Culture 4 (1): $123-50$.

2005 'God: a brief history with a cognitive explanation of the concept.' Temenos 41 (1): 77-128.

2009 Supernatural Agents: Why We Believe in Souls, Gods, and Buddhas. Oxford: Oxford University Press

\section{Reber, Arthur C.}

1993 Implicit Learning and Tacit Knowledge. Oxford: Oxford University Press.

\section{Rozin, Paul, Linda Millman \& Carol Nemeroff}

1986 'Operation of the laws of sympathetic magic in disgust and other domains.' Journal of Personality and Social Psychology 50 (4): 703-12.

\section{Rozin, Paul \& Carol Nemeroff}

1990 'The laws of sympathetic magic: a psychological analysis of similarity and contagion.' In: James W. Stigler, Richard A. Shweder \& Gilbert Herdt (eds), Cultural Psychology: Essays on Comparative Human Development. 205-32. Cambridge: Cambridge University Press. 


\section{Sloman, Steven A.}

1996 'The empirical case for two systems of reasoning.' Psychological Bulletin 119 (1):3-22.

\section{Sperber, Dan}

1997 'Intuitive and reflective beliefs.' Mind and Language 12 (1): 67-83.

\section{Stanovich, Keith E.}

1999 Who is Rational? Studies of Individual Differences in Reasoning. Mahway, NJ: Lawrence Erlbaum Associates.

\section{Sutcliffe, Steven}

2003 Children of the New Age. London \& New York: Routledge.

\section{Tremlin, Todd}

2006 Minds and Gods: The Cognitive Foundations of Religion. New York: Oxford University Press.

\section{Tylor, Edward B.}

1871 Primitive Culture: Researches into the Development of Mythology, Philosophy, Religion, Art, and Custom. 2 vols. London: John Murray.

Visala, Aku

2009 Religion Explained? A Philosophical Appraisal of the Cognitive Science of Religion. Academic dissertation. Department of Systematic Theology, University of Helsinki. (Published by Ashgate in 2011.)

\section{Wegner, Daniel}

2002 The Illusion of Conscious Will. Cambridge, MA: MIT Books.

\section{Whitehouse, Harvey}

2004 Modes of Religiosity: A Cognitive Theory of Religious Transmission. Walnut Creek: Alta Mira Press.

Woodhead, Linda \& Paul Heelas

2000 Religion in Modern Times. Oxford: Blackwell Publishers. 